\title{
Online Fault Detection and Tolerance for Photovoltaic Energy Harvesting Systems
}

\author{
Xue Lin', Yanzhi Wang', Di Zhu', Naehyuck Chang ${ }^{2}$, and Massoud Pedram \\ ${ }^{1}$ Department of Electrical Engineering, University of Southern California, Los Angeles, CA, USA \\ ${ }^{2}$ Seoul National University, Seoul, Korea \\ 1\{xuelin, yanzhiwa, dizhu, pedram\}@usc.edu, ${ }^{2}$ naehyuck@elpl.snu.ac.kr
}

\begin{abstract}
Photovoltaic energy harvesting systems (PV systems) are subject to PV cell faults, which decrease the efficiency of PV systems and even shorten the PV system lifespan. Manual PV cell fault detection and elimination are expensive and nearly impossible for remote PV systems, e.g., PV systems on satellites. Therefore, online fault detection techniques and fault tolerance solutions are needed that can detect and tolerate PV cell faults without manual intervention. In this work, we present an online fault detection and tolerance technique for remote PV systems, which is capable of dynamically locating faulty PV cells and tolerating PV cell faults. More precisely, we present a modified PV panel structure and an efficient algorithm for our online fault detection and tolerance. Our fault detection and tolerance technique reduces output power degradation due to PV cell faults in a PV system by up to $81.31 \%$.
\end{abstract}

\section{Categories and Subject Descriptors}

B.8.1 [Performance and Reliability]: Reliability, Testing, and Fault-Tolerance.

\section{General Terms}

Algorithms, Management, Performance, Reliability.

\section{Keywords}

Photovoltaic System, Fault Detection, Fault Tolerance, Photovoltaic Panel Reconfiguration.

\section{INTRODUCTION}

Due to the growth of world energy consumption and concerns about environmental effects of fossil fuels, human society is in desperate need of renewable energy sources (e.g., solar, wind, geothermal), which are clean and eco-friendly. Among renewable energy sources, photovoltaic (PV) energy draws significant attention since solar energy is accessible and abundant. Various scales of PV energy generation systems (PV systems) have been implemented for practical applications, such as satellites, street lamps, vehicles, and power stations.

Solar irradiance is changing frequently according to the time of day and weather conditions (e.g., clouds), and the output power of PV systems is directly dependent on solar irradiance. Standalone PV systems are equipped with electrical energy storage elements (e.g., batteries, supercapacitors) to store the excess electrical

Permission to make digital or hard copies of all or part of this work for personal or classroom use is granted without fee provided that copies are not made or distributed for profit or commercial advantage and that copies bear this notice and the full citation on the first page. To copy otherwise, to republish, to post on servers or to redistribute to lists, requires prior specific permission and/or a fee.

IEEE/ACM International Conference on Computer-Aided Design (ICCAD) 2012, November 5-8, 2012, San Jose, California, USA

Copyright (C) 2012 ACM 978-1-4503-1573-9/12/11 ...\$15.00 energy harvested under high levels of solar irradiance and mitigate the output power shortage under low levels of solar irradiance. Moreover, PV panels exhibit highly non-linear powervoltage $(\mathrm{P}-\mathrm{V})$ characteristics that vary with solar irradiance. Therefore, maximum power point tracking (MPPT) techniques are demanded to guarantee maximum output power of PV panels [1], [2]. The recent maximum power transfer tracking (MPTT) technique, which takes into account the charger efficiency variation, is more effective [3].

PV systems are subject to PV cell faults, which attribute to external causes (e.g., hit by foreign objects) and internal causes (e.g., hot spots on PV cells.) PV cell faults can decrease system efficiency and shorten the system lifespan. As a result, fault detection and fault tolerance techniques are necessary for PV system maintenance. Moreover, in some remote PV systems (e.g., PV systems for satellites), manual fault detection and elimination is expensive and nearly impossible. Therefore, online fault detection and tolerance techniques are preferred to minimize the negative effects of PV cell faults without manual intervention.

Several PV cell fault diagnosis techniques are proposed [4], [5], [6]. However, these techniques suffer from one or more of the following limitations.

a) They can only determine the existence of PV cell faults without locating these faults [4], [5].

b) There is a lack of fault tolerance solution, which can minimize negative effects of PV cell faults and improve economic benefits of PV systems [4], [5], [6].

c) Additional equipment (e.g., signal generators, signal analysis devices) is needed to perform fault diagnosis [6].

In this paper, we present an online fault detection and tolerance technique that detects the locations of PV cell faults and reconfigures the PV panel for fault tolerance to maintain the maximum achievable efficiency of PV system with PV cell faults. We provide both a structural support and an efficient algorithm that can be integrated into the system controller with negligible time overhead. Experimental results demonstrate that our fault detection and tolerance technique reduces output power degradation due to PV cell faults in a PV system by up to $81.31 \%$ compared with a baseline system without the fault detection and tolerance technique.

\section{COMPONENT MODELS}

\subsection{PV Cell Model and Characterization}

An equivalent circuit model and the symbol of a PV cell are shown in Figure 1. $V_{p v}^{c}$ and $I_{p v}^{c}$ denote the output voltage and current of a PV cell, respectively. Current-Voltage (I-V) characteristics of a PV cell is given by

$$
\begin{aligned}
I_{p v}^{c} & =I_{L}-I_{d}-I_{s h} \\
& =I_{L}(G)-I_{0}(T)\left(e^{\left(V_{p v}^{c}+I_{p v}^{c} \cdot R_{S}\right) \cdot \frac{q}{A k T}}-1\right)-\frac{V_{p v}^{c}+I_{p v}^{c} \cdot R_{S}}{R_{p}},
\end{aligned}
$$




$$
I_{L}(G)=\frac{G}{G_{S T C}} \cdot I_{L}\left(G_{S T C}\right)
$$

and

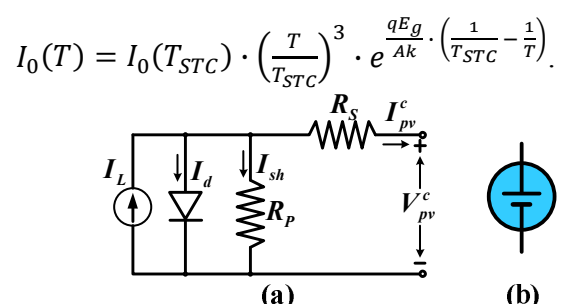

Figure 1. (a) Equivalent circuit and (b) symbol of a PV cell.

The symbols in (1), (2), and (3) are summarized as follows: $G$ is the solar irradiance level; $T$ is the PV cell temperature; $q$ is the charge of an electron; $E_{g}$ is the bandgap and $k$ is the Boltzmann's constant. STC stands for the standard test condition where $G_{S T C}=1000 \mathrm{~W} / \mathrm{m}^{2}$ and $T_{S T C}=25^{\circ} \mathrm{C}$. For rest of the parameters, i.e., photo-generated current at STC $I_{L}\left(G_{S T C}\right)$, dark saturation current at STC $I_{0}\left(T_{S T C}\right)$, PV cell series resistance $R_{S}, \mathrm{PV}$ cell parallel resistance $R_{p}$, and diode ideality factor $A$, we adopt the method in [7] to extract their values.
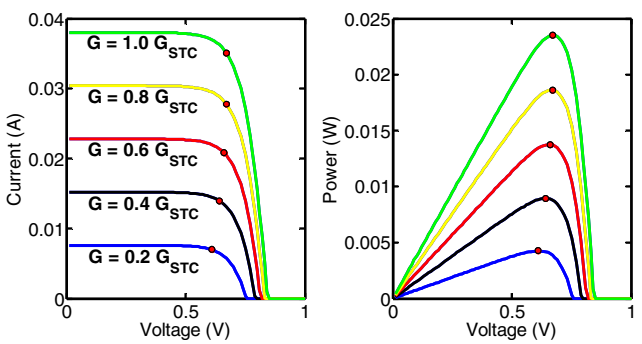

Figure 2. I-V and P-V output characteristics of a PV cell under different solar irradiance levels.

The PV cell I-V and P-V output characteristics under the same temperature $T_{S T C}$ but different solar irradiance levels are shown in Figure 2. The PV cell exhibits a non-linear output current and voltage relationship. There is a maximum power point (MPP) under any solar irradiance level, where the output power of a PV cell is maximized. MPPs are labeled by red dots in Figure 2.

\subsection{PV Panel with PV Cell Fault}

A PV panel consists of PV cells connected in a series-parallel $N \times M$ configuration. Figure 3 shows a $4 \times 4 \mathrm{PV}$ panel, where there are four $P V$ cell groups connected in series, and each $\mathrm{PV}$ cell group has four PV cells connected in parallel. $V_{p v}$ and $I_{p v}$ are the output voltage and current of a PV panel, respectively.

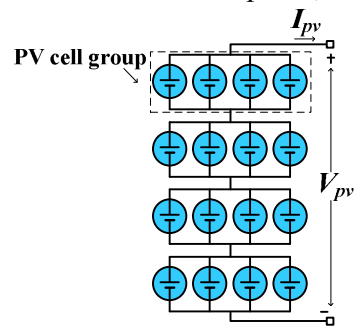

Figure 3. The configuration of a $4 \times 4 \mathrm{PV}$ panel.

A PV cell fault can attribute to external causes (e.g., hit by foreign objects) or internal causes (e.g., PV cell hot spots). A PV cell fault is equivalent to an open circuit at the position of the faulty PV cell. The PV cell fault does serious harm to the PV panel in two aspects: (a) A PV cell fault leads to a reverse bias operation of the PV cell group with the faulty PV cell, which may result in hot spots and potentially more faulty PV cells in that PV cell group. (b) The PV cell group with the faulty PV cell limits the output current of the whole PV panel because all the PV cell groups are connected in series. Therefore, the PV panel with a faulty PV cell suffers from output power degradation much higher than the MPP power of a single PV cell.

Integration of a bypass diode with each PV cell in the PV panel can solve the reverse bias operation problem [8]. Figure 4 shows the bypass diode connected in parallel with a PV cell. We will use the new PV cell symbols in a PV panel to avoid the reverse bias operation problem.

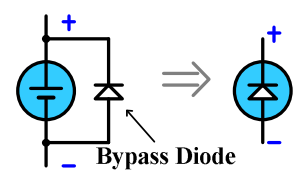

Figure 4. A PV cell integrated with a bypass diode.

However, the PV panel with a faulty PV cell still suffers from output power degradation that is much higher than the MPP power of a single PV cell despite the use of bypass diodes. Figure 5 shows the P-V output characteristics of a $4 \times 4 \mathrm{PV}$ panel with and without a PV cell fault. The PV panel output power degradation is calculated as the difference between the two MPPs labeled with red dots on the P-V output characteristics in Figure 5. Ideally, if only one PV cell is faulty in the $4 \times 4$ PV panel, the PV panel should suffer from a power degradation of $1 / 16=6.3 \%$. However, the practical PV panel output power degradation due to a faulty PV cell is $16.5 \%$. The objective of this work is to reduce the PV panel output power degradation to the largest extent.

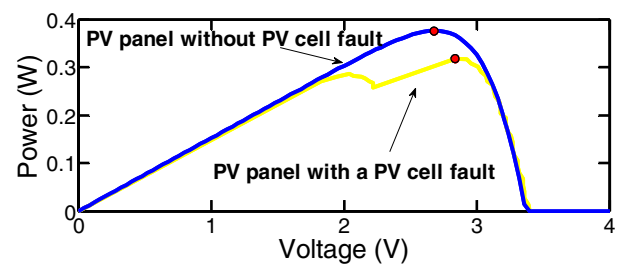

Figure 5. The P-V output characteristics of a $4 \times 4 \mathrm{PV}$ panel with/without a PV cell fault.

\subsection{Charger Model}

The PV cell I-V characteristics vary with solar irradiance level and temperature. We use a charger between the $N \times M$ PV panel and the load or energy storage element to control the PV panel operation point $\left(V_{p v}, I_{p v}\right)$. The charger model is introduced in [9]. $V_{\text {in }}, I_{\text {in }}, V_{\text {out }}$, and $I_{\text {out }}$ denote the input voltage, input current, output voltage and output current of the charger, respectively. The input ports of the charger are connected to the PV panel, and the output ports are connected to the load. The system controller adjusts the charger output current and thus maintaining the operating point of the PV panel. The power consumption of the charger $P_{\text {conv }}$ is a function of $V_{\text {in }}, I_{\text {in }}$, and $I_{\text {out }}$ [9]. $P_{\text {conv }}$ also satisfies the energy conservation law

$$
V_{\text {in }} \cdot I_{\text {in }}=P_{\text {conv }}+V_{\text {out }} \cdot I_{\text {out }} \text {. }
$$

We calculate the charger output current $I_{\text {out }}$ as a function of $V_{\text {in }}, I_{\text {in }}$, and $V_{\text {out }}: I_{\text {out }}=$ Chg_Out_I $I\left(V_{\text {in }}, I_{\text {in }}, V_{\text {out }}\right)$.

\subsection{PV System}

The architecture of the target PV system is shown in Figure 6 that consists of a PV panel, a charger and a battery. The PV panel contains $N \times M$ series-parallel connected PV cells, where $M$ PV cells are connected in parallel to form a PV cell group and $N$ PV 
cell groups are connected in series. The PV cells have been integrated with bypass diodes as mentioned in Section 2.2. $V_{b a t}$ and $I_{b a t}$ denote the terminal voltage and charging current of the battery, respectively. The input voltage, input current, output voltage and output current of the charger are $V_{p v}, I_{p v}, V_{b a t}$ and $I_{\text {bat }}$, respectively, in this PV system architecture. According to (4),

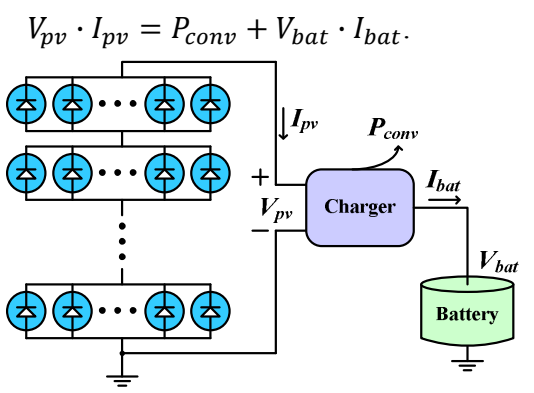

Figure 6. PV system architecture.

Our online fault detection and tolerance technique is performed periodically as routine maintenance. We assume that at most one PV cell fault occurs in a maintenance cycle. This assumption is valid because we may perform more frequent maintenance until the assumption is met. We need to locate only one possible PV cell fault at a time. The target PV panel originally has an $N \times M$ balanced configuration. If there is no faulty PV cell in the PV panel, all the PV cells can work at their MPPs simultaneously by setting a proper operating point of the PV panel, and therefore, the PV panel produces the maximum output power. However, if PV cell faults occur to the $N \times M$ PV panel, the PV panel suffers from significant output power degradation due to the seriesparallel configuration of these PV cells.

The principle of our fault detection and tolerance technique is as follows. Given $G$ and $T$, the system controller calculates the ideal output power from a set of PV cells in the panel based on the configuration of those PV cells and the assumption that there is no faulty PV cell among those PV cells. The system controller then compares the ideal output power with the practical output power of this set of PV cells. If the difference is larger than a predefined error, there must be a faulty PV cell among this set of PV cells. The size of the suspicious PV cell set shrinks to one after several trials of PV cell fault search. After locating the faulty PV cell, our fault tolerance method changes the $N \times M \mathrm{PV}$ panel into an $N^{\prime} \times M^{\prime}$ one, where $N^{\prime} \times M^{\prime} \leq N \times M-1$ and the faulty PV cell is excluded from the new PV panel configuration, to mitigate the effect of the faulty $\mathrm{PV}$ cell and reduce the output power degradation of the PV panel.

\section{STRUCTURAL SUPPORT}

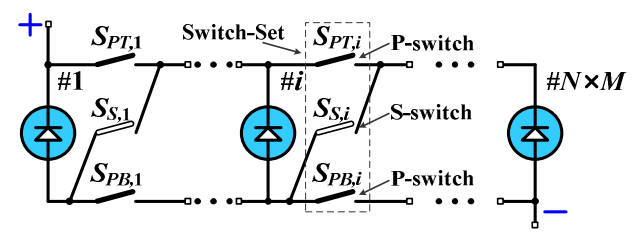

Figure 7. PV panel structure.

We employ a modified PV panel structure that can achieve an $N \times M$ configuration for normal PV system operation as well as more flexible PV cell configurations for the online fault detection and tolerance technique. The modified PV panel structure is introduced in [10] to improve the efficiency of PV systems. Figure 7 shows the modified PV panel structure in which each $i$-th PV cell except for the last one is integrated with three switches, i.e., a S-switch $S_{S, i}$, a top P-switch $S_{P T, i}$, and a bottom P-switch $S_{P B, i}$. Although the PV cells are labeled with increasing indices from left to right, the physical locations of PV cells in a PV panel do not necessarily follow a left to right ordering. Figure 7 presents the logical connection of PV cells and switches rather than the physical locations of them. The details of achieving the $N \times M$ configuration for normal PV system operation are in [10].

\subsection{Structural Support for Fault Detection}

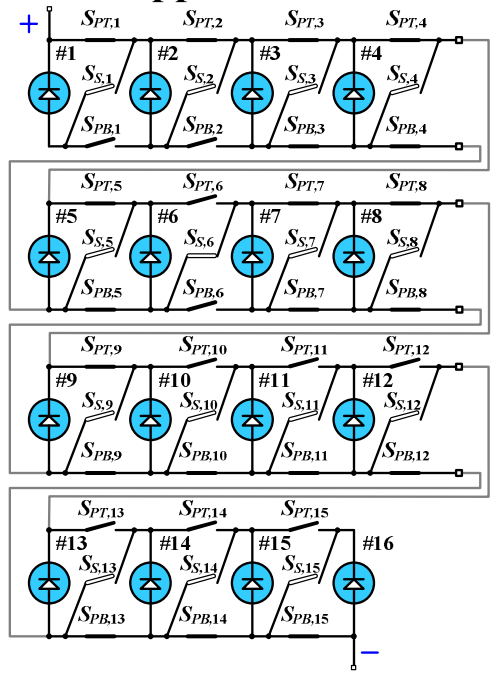

Figure 8. An example of achieving a $2 \times 4$ configuration for the 16-cell PV panel with the modified PV panel structure.

The modified PV panel structure is also useful in fault detection process, where a set of PV cells forms a configuration for measuring their $\mathrm{P}-\mathrm{V}$ characteristics and determining whether there is a PV cell fault. We denote the PV cell index set by $\mathrm{A}=$ $\{1,2,3, \cdots, N \times M\}$. In a trial of PV cell fault search, $K \times M \mathrm{PV}$ cells $(K \leq N)$ with consecutive indices are selected. There might be a PV cell fault in these PV cells. Therefore, these PV cells need to form a $K \times M$ configuration which is then connected with the charger for further measurement, while the rest PV cells in the panel are excluded for this trial of PV cell fault search. Figure 8 shows an example of achieving a $2 \times 4$ configuration out of the 16-cell PV panel. Suppose that the system controller is checking PV cells 3-10. Then PV cells 3-10 forms a $2 \times 4$ configuration by setting the switches as shown in Figure 8. In Figure 8 except for PV cells 3-10, the rest PV cells are disconnected from the panel. In this way, the system controller can focus on PV cells 3-10 to determine whether there is a PV cell fault among those PV cells.

\subsection{Structural Support for Fault Tolerance}

After the identification of faulty PV cells which cause open circuits at their positions, the modified PV panel structure as shown in Figure 7 can tolerate the PV cell faults by changing the configuration of the PV panel into a desirable one. For an $(N \times M)$-cell PV panel, if there are $L$ faulty PV cells that were identified as faulty during several runs of our fault detection method, the modified PV structure can achieve an $N^{\prime} \times M^{\prime}$ configuration for the PV panel where $N^{\prime} \times M^{\prime} \leq N \times M-L$ and in which only the normal PV cells are used. As an illustration, Figure 9 shows how to achieve a $5 \times 3$ configuration out of the 16-cell PV panel with one faulty PV cell, i.e., PV cell 8 . The first PV cell group consists of PV cells 1-3, the second PV cell group consists of PV cells 4-6, and the third PV cell group consists of PV cells 7, 9, and 10 . The faulty PV cell 8 is an open circuit, so 
$S_{P T, 8}$ and $S_{P B, 8}$ are on while $S_{S, 8}$ are off. In this way PV cell 7 and PV cell 9 are connected in parallel.

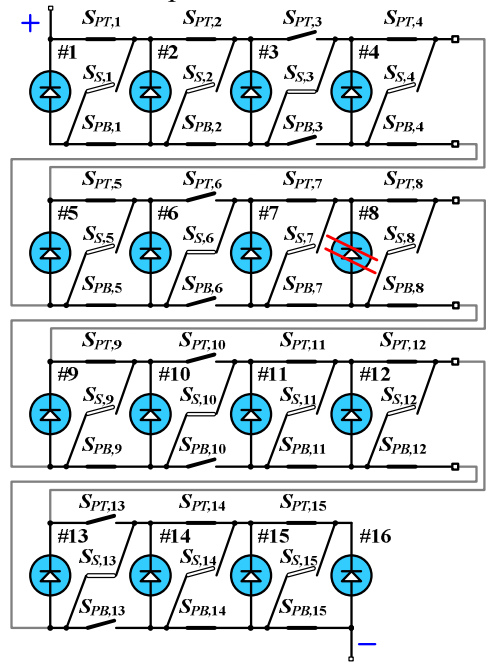

Figure 9. An example of PV cell fault tolerance with the modified PV panel structure.

\section{FAULT DETECTION AND TOLERANCE ALGORITHM}

After last run of online fault detection and tolerance, the PV panel ended up in an $N \times M$ configuration. Now after a time period of $T_{d}$, we suspect that a new PV cell fault might occur, and therefore the online fault detection and tolerance might need to be executed. The necessity of executing fault detection and tolerance can be decided as follows.

a) The system controller estimates the ideal maximum output power of the PV panel $P_{\text {ideal }}=i d e a l \_p o w e r(G, T, N, M)$ as a function of $G, T$, and the configuration, assuming that all $N \times M$ PV cells function properly.

b) The system controller tracks the real maximum output power of the PV panel $P_{\text {real }}$ using the MPPT technique.

c) If $P_{\text {real }}<P_{\text {ideal }}-\varepsilon$ where $\varepsilon$ is a predefined system error, there must be a faulty PV cell among the $N \times M$ PV cells and the online fault detection and tolerance must be executed; otherwise, there is no need to execute the online fault detection and tolerance.

\subsection{Fault Detection Algorithm}

The basic idea of fault detection is as follows. A detection target of $k \times M \mathrm{PV}$ cells is selected out of the $N \times M \mathrm{PV}$ cells, and these $k \times M \mathrm{PV}$ cells can be detected for PV cell fault using Procedure 1. As the detection target narrows down, the faulty PV cell can be identified.

Procedure 1:
1. Form a $k \times M$ configuration of these PV cells.
2. The ideal maximum output power of these $k \times M$ PV cells $P_{\text {ideal }}=$
ideal_power $(G, T, k, M)$ is estimated by system controller.
3. The system controller tracks the real maximum output power $P_{\text {real }}$ of
these $k \times M$ PV cells using the MPPT technique.
4. If $P_{\text {real }}<P_{\text {ideal }}-\varepsilon$ where $\varepsilon$ is a predefined system error, there is a
faulty PV cell among these $k \times M$ PV cells.
Return 1 .
Else there is no faulty PV cell among these PV cells.
Return 0 .

The $N \times M$ PV panel is considered as a PV cell matrix which has $N$ rows and $M$ columns. The rows and columns of the $N \times M$ PV panel are decided according to the configuration of the PV panel instead of the physical locations of PV cells. The fault detection algorithm first determines which row the faulty PV cell is located at (row search), and then determines which column the faulty PV cell is located at (column search).

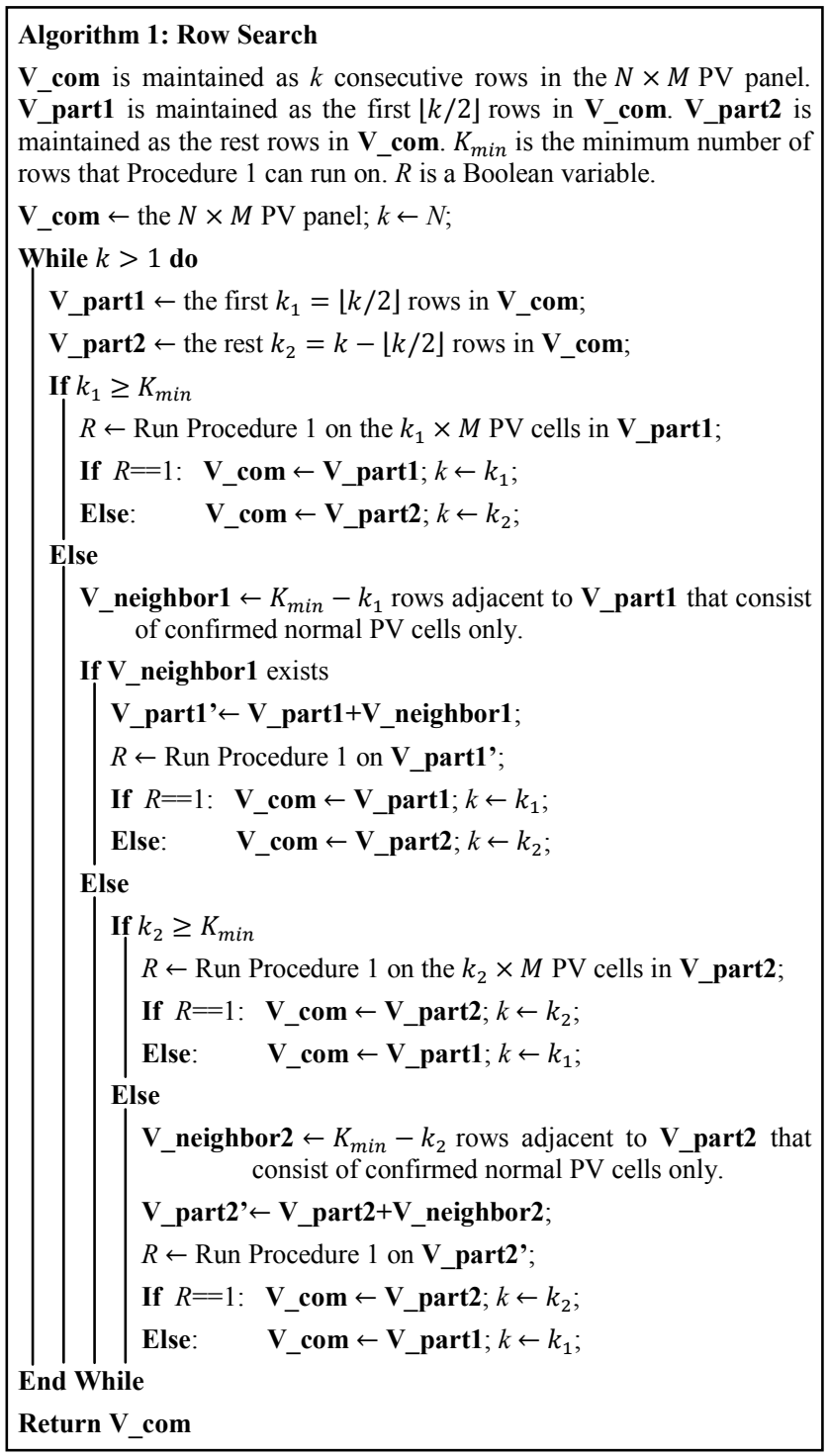

Algorithm 1 is for the row search. We start with the $N \times M$ PV panel. First we bisect the rows into: the rows 1 to $[N / 2\rfloor$ and the rows $[N / 2\rfloor+1$ to $N$. We run Procedure 1 on the first part. If there is a PV cell fault within the first part, we can confirm that there is no faulty PV cell in the second part. Then we bisect the rows in the first part for further PV cell fault search. If there is no faulty PV cell within the first part, we can confirm that there is a faulty PV cell in the second part. Procedure 1 cannot run on a configuration smaller than $K_{\min } \times M$, where $K_{\text {min }}$ is the minimum number of rows that Procedure 1 can run on. That is because the output current and voltage of a very small configuration of $\mathrm{PV}$ cells is too low to be controlled by the charger. Therefore, if we need to run Procedure 1 on $k \times M \mathrm{PV}$ cells where $k<K_{\min }$ to decide whether there is a faulty PV cell among these $k \times M \mathrm{PV}$ cells, we must "borrow" $K_{\min }-k$ adjacent rows which consist of confirmed normal PV cells.

After implementation of Algorithm 1, V_com contains the PV cell row with the faulty PV cell. Figure 10 is an illustration of PV cell fault row search, where $N=4, M=4$, and $K_{\min }=2$. First, 
the $4 \times 4$ PV panel is bisected into Part A and the rest rows. After running Procedure 1 on Part A, we confirm Part A contains the faulty PV cell. Then we bisect Part A into Part B and Part C. We would like to run Procedure 1 on Part B, however, Part B has a size of $1 \times 4$ (smaller than $\left.K_{\min } \times M\right)$. We must borrow one adjacent row for Part $\mathrm{B}$, which is Part $\mathrm{C}$. But Part $\mathrm{C}$ may contain the faulty PV cell, and cannot be borrowed for Part B. Therefore we choose Part $\mathrm{C}$ for fault detection instead of Part B. Although Part $\mathrm{C}$ is also smaller than $K_{\min } \times M$ for running Procedure 1 , we can borrow the third row for Part $\mathrm{C}$. Therefore, we run Procedure 1 on Part $\mathrm{C}$ plus the third row. After that we know there is the faulty PV cell within Part C.

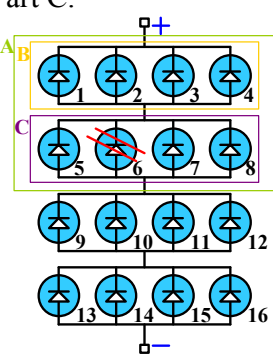

Figure 10. An illustration of fault detection: row search.

After finding the row containing the faulty PV cell, we need do column search to decide column position of the faulty PV cell. Algorithm 2 is for the column search. A_com returns the faulty PV cell after implementation of Algorithm 2. Figure 11 is an illustration of PV cell fault column search. We have known that the second row contains the faulty PV cell from the row search. First, we bisect the second row into Part A and Part B. We would like to run Procedure 1 on Part A, however, Part A has a size of $1 \times 2$ smaller than $2 \times 4\left(K_{\min } \times M\right)$. We must borrow six

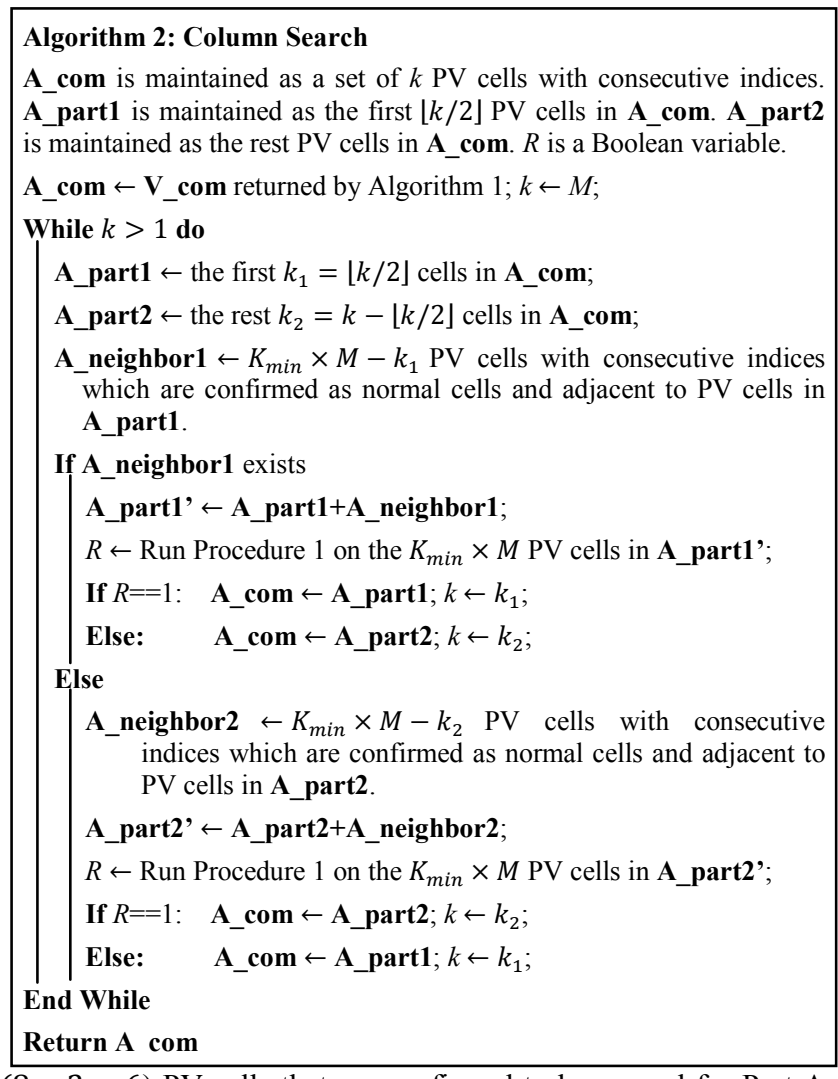

and these six cells together with Part A cells must have consecutive indices, otherwise, we cannot form a $2 \times 4$ configuration out of the PV panel. We can only borrow PV cells 1-4 for Part A. Then we choose Part B for fault detection. We form a $2 \times 4$ configuration of PV cells 7-14 and run Procedure 1 on it. We find no faulty PV cell among PV cells 7-14. Therefore, we know that the faulty PV cell exists in Part A. Next, we bisect Part A into Part C and Part D. We still cannot detect PV cell fault on Part C. Then we form a $2 \times 4$ configuration of PV cells 6-13 and run Procedure 1 on it. We find a faulty PV cell among PV cells 6-13 (i.e., the faulty PV cell is PV cell 6).

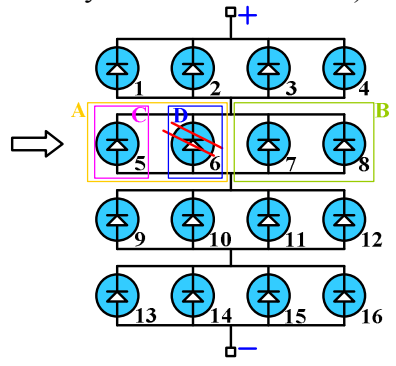

Figure 11. An illustration of fault detection: column search.

\subsection{Fault Tolerance Algorithm}

After the implementation of fault detection algorithm, we can identify one faulty PV cell. However, there may be more than one faulty PV cell in the PV panel which were identified during previous runs of fault detection and tolerance algorithms. Suppose the original PV panel has $N \times M$ PV cells in total and $L$ faulty PV cells have been identified. We know the indices of these $L$ faulty PV cells. The PV panel can form any $N^{\prime} \times M^{\prime}$ configuration, where $N^{\prime} \times M^{\prime} \leq N \times M-L$ and only the normal PV cells are used. The fault tolerance algorithm aims at finding the optimal $N^{\prime}$ and $M^{\prime}$ values such that the system output power is maximized, given current $G$ and $T$ as well as the battery terminal voltage $V_{b a t}$.

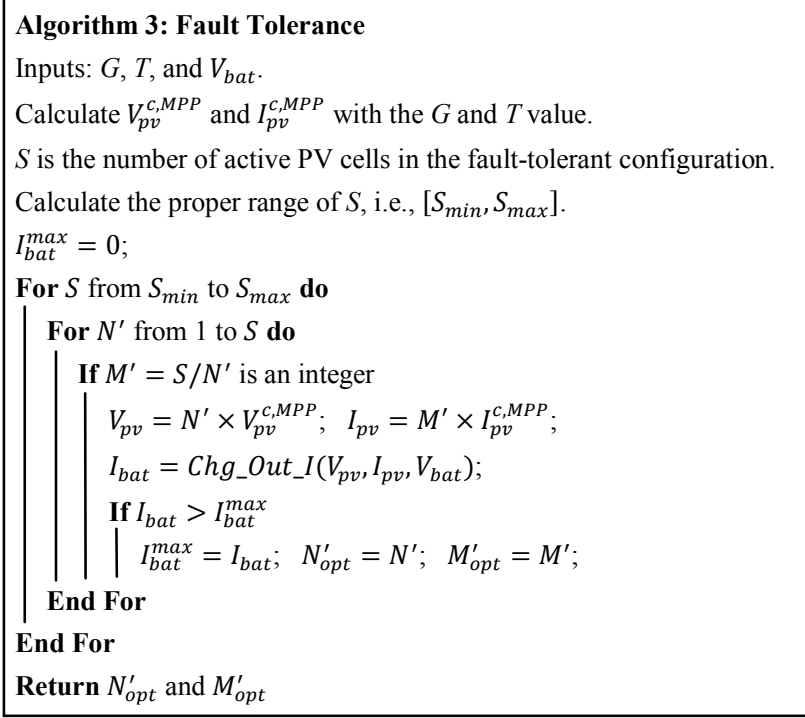

Algorithm 3 is the fault tolerance algorithm. A proper range for $S$, i.e., $\left[S_{\min }, S_{\max }\right]$ can be calculated as $S_{\max }=N \times M-L$ and $S_{\text {min }}=N \times M-3 L$. We use $V_{p v}^{c, M P P}$ and $I_{p v}^{c, M P P}$ to denote the MPP of a PV cell under $(G, T)$. Maximizing the PV system output power $I_{b a t} \cdot V_{b a t}$ is equivalent to maximizing $I_{b a t}$. Then for each possible $S$ value, we find its two factors $N^{\prime}$ and $M^{\prime}$ and calculate the corresponding $I_{b a t}$ value. When $I_{b a t}$ is maximized, the 
corresponding $N^{\prime}$ and $M^{\prime}$ is recorded as the optimal $N_{o p t}^{\prime}$ and $M_{\text {opt }}^{\prime}$ values.

\section{EXPERIMENTAL RESULTS}

We compare performances of the PV system with the proposed online fault detection and tolerance technique and the baseline PV system without fault detection and tolerance technique. The proposed PV system employs the PV panel structure in Figure 7, where there are $(N \times M=) 100$ PV cells. The baseline PV system employs a $(N \times M=) 20 \times 5$ fixed configuration for the PV panel. PV cells in both systems are integrated with bypass diodes to avoid the reverse bias operation. The baseline PV system is integrated with MPPT technique. The proposed PV system is integrated with the online fault detection and tolerance technique.

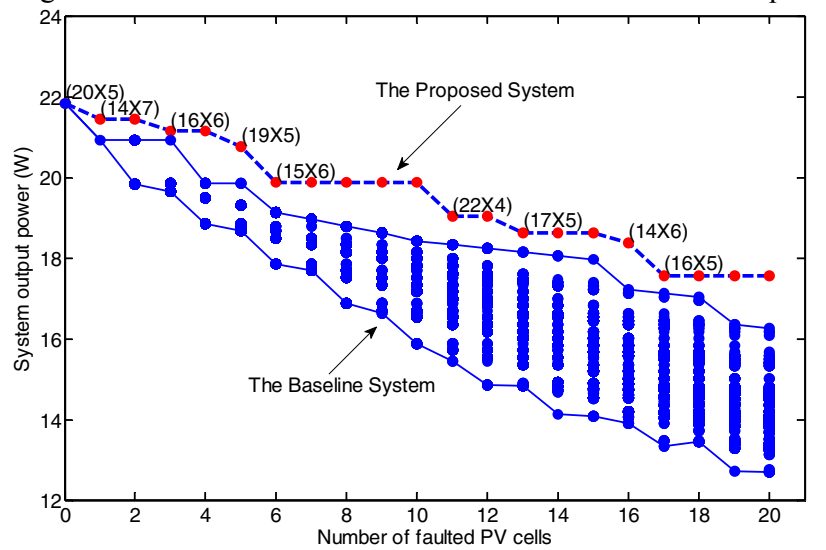

Figure 12. Output power of the proposed system and baseline system with different number of faulty PV cells.

Figure 12 shows the output power of the proposed system and baseline system as a function of the number of faulty PV cells. We use $\left(G_{S T C}, T_{S T C}\right)$ as the test condition and $V_{b a t}=10 \mathrm{~V}$. The red dots represent the output power of the proposed system and the optimal PV panel configurations obtained by fault tolerance algorithm are labeled beside the red dots. The output power of the proposed system is related to the number of faulty PV cell, but unrelated to the locations of faulty PV cells. The blue dots present the output power of the baseline system, which is related to both the number of faulty PV cells and the locations of faulty PV cells. Therefore, for a given number of faulty PV cells, 1000 groups of the locations of faulty PV cells are randomly selected, which results in 1000 points (some of which are overlapped) under a given number of faulty PV cells.

Table 1. Reduction of power loss in the proposed system.

\begin{tabular}{|c|c|c|c|c|c|}
\hline $\begin{array}{c}\text { Num of faulty } \\
\text { PV cells }\end{array}$ & 2 & 6 & 10 & 14 & 18 \\
\hline $\begin{array}{c}\text { Power loss of } \\
\text { our system(W) }\end{array}$ & 0.3734 & 1.9567 & 1.9567 & 3.1885 & 4.2585 \\
\hline $\begin{array}{c}\text { Max power loss } \\
\text { of baseline(W) }\end{array}$ & 1.9978 & 3.9634 & 5.9406 & 7.7090 & 8.3875 \\
\hline $\begin{array}{c}\text { Min power loss } \\
\text { of baseline(W) }\end{array}$ & 0.8972 & 2.6871 & 3.4074 & 3.7584 & 4.7883 \\
\hline $\begin{array}{c}\text { Max power loss } \\
\text { reduction }\end{array}$ & $81.31 \%$ & $50.63 \%$ & $67.06 \%$ & $58.64 \%$ & $49.23 \%$ \\
\hline $\begin{array}{c}\text { Min power loss } \\
\text { reduction }\end{array}$ & $58.38 \%$ & $27.18 \%$ & $42.57 \%$ & $15.16 \%$ & $11.06 \%$ \\
\hline
\end{tabular}

Table 1 summarizes the reduction of power loss by the online fault detection and tolerance technique. The first row is the number of faulty PV cells. The second row is the power loss of our proposed system compared to a system without PV cell fault. The third and fourth rows are the maximum and minimum power loss of the baseline system compared to a system without PV cell fault, which correspond to the lower bound and upper bound in Figure 12, respectively. The fifth and sixth rows are the reduction of power loss in the proposed system compared with the third row and the fourth row, respectively. For example, when there are two faulty PV cells (the second column), the power loss of the proposed system is $0.3734 \mathrm{~W}$, which is only $18.69 \%$ of the maximum power loss of the baseline system (i.e., $1.9978 \mathrm{~W}$ ). Therefore, the power loss is reduced by $81.31 \%$, demonstrating the effectiveness of our online fault detection and tolerance technique.

\section{CONCLUSION}

We propose an online fault detection and tolerance technique for PV systems to reduce the output power degradation due to PV cell faults. We provide both the structural support as well as an efficient algorithm. This is the first work that introduces online reconfiguration for PV cell fault detection and tolerance.

\section{ACKNOWLEDGMENTS}

This work is sponsored in part by a grant from the CISE directorate of the National Science Foundation in USA, the Brain Korea 21 Project, the National Research Foundation of Korea (NRF) grant funded by the Korean Government (MEST) (No. 2011-0016480), and ICT at Seoul National University.

\section{REFERENCES}

[1] N. Femia, G. Petrone, G. Spagnuolo, and M. Vitelli, "Optimization of perturb and observe maximum power point tracking method," IEEE T. on Power Electronics, 2005.

[2] F. Liu, S. Duan, F. Liu, B. Liu, and Y. Kang, "A variable step size INC MPPT method for PV systems," IEEE T. on Industrial Electronics, 2008.

[3] Y. Kim, N. Chang, Y. Wang, and M. Pedram, "Maximum power transfer tracking for a photovoltaic-supercapacitor energy system," Proc. of the Int'l Symposium on Low Power Electronics and Design, Aug. 2010.

[4] A. Houssein, N. Heraud, I. Souleiman, and G. Pellet, "Monitoring and fault diagnosis of photovoltaic panels," Int'l Symposium on Environment Friendly Energies in Electrical Applications, Nov. 2010.

[5] K. H. Chao, C. J. Li, and S. H. Ho, "Modeling and fault simulation of photovoltaic generation systems using circuit-based model," Proc. of IEEE Int'l Conf. on Sustainable Energy Technologies, Nov. 2008.

[6] L. Schirone, F. P. Califano, U. Moschella, U. Roccs, "Fault finding in a $1 \mathrm{MW}$ photovoltaic plant by reflectometry," IEEE Conf. on Photovoltaic Energy Conversion, Dec. 1994.

[7] W. Lee, Y. Kim, Y. Wang, N. Chang, M. Pedram, and S. Han, "Versatile high-fidelity photovoltaic module emulation system," Proc. of the Int'l Symposium on Low Power Electronics and Design, Aug. 2011.

[8] M. S. Swaleh, and M. A. Green, "Effect of shunt resistance and bypass diodes on the shadow tolerance of solar cell modules," Solar Cells, vol. 5, no. 2, 1982.

[9] Y. Wang, Y. Kim, Q. Xie, N. Chang, and M. Pedram, "Charge migration efficiency optimization in hybrid electrical energy storage (HEES) systems," Proc. of the Int'l Symposium on Low Power Electronics and Design, Aug. 2011.

[10] Y. Wang, X. Lin, Y. Kim, N. Chang, and M. Pedram, "Enhancing efficiency and robustness of a photovoltaic power system under partial shading," Proc. of the Int'l Symposium on Quality Electronic Design, Mar. 2012. 